\title{
Light induced electrical and macroscopic changes in hydrogenated polymorphous silicon solar cells
}

\author{
K.H. Kim ${ }^{1,2}$, a , E.V. Johnson ${ }^{2}$, A. Abramov ${ }^{2}$, and P. Roca i Cabarrocas ${ }^{2}$ \\ 1 TOTAL S.A., Gas \& Power - R\&D Division, Courbevoie, France \\ 2 Laboratoire de Physique des Interfaces et des Couches Minces (UMR 7647 CNRS), École Polytechnique, 91128 Palaiseau, \\ France
}

Received: 5 August 2011 / Accepted: 16 April 2012

Published online: 18 July 2012

\begin{abstract}
We report on light-induced electrical and macroscopic changes in hydrogenated polymorphous silicon (pm-Si:H) PIN solar cells. To explain the particular light-soaking behavior of such cells - namely an increase of the open circuit voltage $\left(V_{o c}\right)$ and a rapid drop of the short circuit current density $\left(J_{s c}\right)-$ we correlate these effects to changes in hydrogen incorporation and structural properties in the layers of the cells. Numerous techniques such as current-voltage characteristics, infrared spectroscopy, hydrogen exodiffusion, Raman spectroscopy, atomic force microscopy, scanning electron microscopy and spectroscopic ellipsometry are used to study the light-induced changes from microscopic to macroscopic scales (up to tens of microns). Such comprehensive use of complementary techniques lead us to suggest that light-soaking produces the diffusion of molecular hydrogen, hydrogen accumulation at $p$-layer/substrate interface and localized delamination of the interface. Based on these results we propose that light-induced degradation of PIN solar cells has to be addressed from not only as a material issue, but also a device point of view. In particular we bring experimental evidence that localized delamination at the interface between the $p$-layer and $\mathrm{SnO}_{2}$ substrate by light-induced hydrogen motion causes the rapid drop of $J_{s c}$.
\end{abstract}

\section{Introduction}

Hydrogenated amorphous silicon (a-Si:H) is widely used as an absorber layer for thin film solar cells. It has generated tremendous scientific and technical interest for two reasons: firstly, a-Si:H has several interesting material properties that have opened up many opportunities for semiconductor device applications, such as a high absorption coefficient and a high optical bandgap. Secondly, the glow discharge deposition technique, also referred to as plasma enhanced chemical vapor deposition (PECVD), has enabled the production of a-Si:H films at a low temperature $\left(\sim 200{ }^{\circ} \mathrm{C}\right)$ over large areas $\left(\sim\right.$ several $\left.\mathrm{m}^{2}\right)$. This low process temperature allows the use of a wide range of low cost substrates such as glass, metal and polymer foils. In addition, a-Si:H can be easily doped and alloyed by adding the appropriate gases to a source gas, usually silane. However, it also displays a serious technical drawback, the so-called Staebler-Wronski effect (SWE) [1] . Indeed, were it not for their light-induced degradation, numerical simulations have predicted that a-Si:H based single junction solar cells could realistically display up to $12 \%$ conversion efficiency [2], thus competing with multicrystalline silicon solar cells. Generally, SWE is synonymous of light-induced creation of metastable defect states,

a e-mail: ka-hyun.kim@polytechnique.edu which work as recombination centers, and it mostly affects the intrinsic layer of PIN solar cells. Therefore, in order to overcome the light-induced degradation, the efforts to improve the stability of a-Si:H involved the development of various types of intrinsic materials using hydrogen diluted silane gas mixtures such as microcrystalline silicon $(\mu \mathrm{c}-\mathrm{Si}: \mathrm{H})$, protocrystalline silicon (pc-Si:H) [3] and polymorphous silicon (pm-Si:H) [4]. This last material is characterized by the formation of silicon nanocrystals in the plasma, which contribute to deposition along with $\mathrm{SiH}_{x}$ radicals. This results in a nanostructured material whose amorphous phase has a medium range order and is more relaxed than that found in standard a-Si:H $[5,6]$. The volume fraction of small crystallites in this material is less than $10 \%$ [7]. Contrary to pc-Si:H, pm-Si:H films can be made thick enough to be used as an absorber layer of thin film solar cells because the microstructure of pm-Si:H does not depend on the thickness of the film or on the nature of the substrate, as its deposition mechanism mainly relies on the silicon nanocrystals synthesized in the plasma, so the nanocrystals distribute to all over the film thickness. Moreover, such deposition conditions coincide with those which result in a higher deposition rate compared to a-Si:H [8]. Through spectroscopic ellipsometry, Rutherford Backscattering and ERDA measurements, it has been shown that pm-Si:H films are denser than a-Si:H films, 
in spite of their high hydrogen content, in the range of 15-20\% [7]. The peculiar structure of pm-Si:H results in a low defect density (of the order of $10^{14} \mathrm{~cm}^{-3} \mathrm{eV}^{-1}$ at Fermi level as measured by SCLC and modulated photocurrent) and higher resistance to light-soaking than a$\mathrm{Si}: \mathrm{H}$ [8-10]. In particular improved hole transport appears to be a key point for the application of this material in solar cells [11].

In this work, we focus on the metastability of pm-Si:H PIN solar cells compared to a-Si:H ones. Our results show that pm-Si:H PIN solar cells have reduced SWE, but show strong changes in their structure, which take place at the early stage ( $\sim$ two hours) of light-soaking. In particular, we aim at explaining the increase in open-circuit voltage $\left(V_{o c}\right)$ and fast decrease of short-circuit current density $\left(J_{s c}\right)$ in pm-Si:H PIN solar cells and establish a relationship between these changes in the electrical properties and structural changes related to hydrogen diffusion to the substrate/ $p$-layer interface and local delamination of the interface during light-soaking.

\section{Experiments}

The PIN solar cells were deposited at $175{ }^{\circ} \mathrm{C}$ by the radio-frequency ( $\mathrm{RF}, 13.56 \mathrm{MHz}$ ) glow discharge PECVD method in a multiplasma-monochamber reactor [12]. Standard a-Si:H was obtained by the dissociation of pure silane at low pressure (50 mTorr) and low RF power density $\left(5 \mathrm{~mW} / \mathrm{cm}^{2}\right)$. Intrinsic pm-Si:H films were deposited under carefully controlled plasma conditions using hydrogen-diluted silane gas mixture. In this work, our pm-Si:H layers were deposited at high pressure of 2 Torr and RF power density of $30 \mathrm{~mW} / \mathrm{cm}^{2}$. The solar cells had the following structure: glass/textured $\mathrm{SnO}_{2}: \mathrm{F} / \mathrm{p}$-type hydrogenated amorphous silicon carbon (a-SiC:H)/a-SiC:H buffer/intrinsic layer/n-type a-Si:H/Al contact. The area of the cells was $0.126 \mathrm{~cm}^{2}$. a-Si:H and pm-Si:H PIN layer stacks were also deposited on Corning Eagle glass, flat TCO and highly resistive $\left(>10^{4} \Omega \mathrm{cm}\right)$ FZ c-Si substrates for more comprehensive studies. The thickness of $p$ and $n$ doped layers were about 170 and $130 \AA$ respectively, and the intrinsic layer thickness varied from 2000 to $5000 \AA$.

To study the macroscopic and microscopic changes in the layers and devices, a number of characterization techniques were employed. For the light-induced degradation studies, sets of current-density-voltage $(J(V))$ measurements at various stages of the light-soaking were performed. The $J(V)$ measurements during the early stages of light-soaking were taken more frequently than later, in order to accurately monitor the dynamics during this critical phase. Between each $J(V)$ measurement, the cells were light-soaked in the open-circuit condition using an OrielApex Xe lamp. The cells were both light-soaked and had their $J(V)$ curves measured under an intense illumination of $200 \mathrm{~mW} / \mathrm{cm}^{2}$ (equivalent to 2 suns), to accelerate light-induced degradation. During light-soaking, the PIN solar cells were fan cooled to limit illumination induced heating. The temperature of the PIN solar cells, measured by PT100 thermometer during light-soaking, stayed under $50{ }^{\circ} \mathrm{C}$

Structural changes during light-soaking were characterized through in-situ micro Raman scattering measurements. A He-Ne laser (632 nm) and a back-scattering collection configuration were used for the Raman measurements. For the light-soaking, a white light source with an intensity of $80 \mathrm{~mW} / \mathrm{cm}^{2}$ was applied from the glass side. The test was done for both a-Si:H and pm-Si:H PIN layer stacks on Corning Eagle glass, and the study on the pm-Si:H PIN was done twice to check its reproducibility. During light-soaking, Raman spectra were measured every five minutes, and for the second pm-Si:H PIN test, the measurement was done every two minutes.

In-situ surface morphology characterization during light-soaking was obtained from AFM measurements. Tapping mode was used to prevent the cantilever from dragging across the surface and resulting in surface damage, as well as providing higher resolution. The samples were exposed to light from the $\mathrm{n}$ layer side, with an intensity of $150 \mathrm{~mW} / \mathrm{cm}^{2}$. The scan rate was chosen to be slow because the surface displays low roughness and small features. Scanning area size was varied from $500 \times 500 \mathrm{~nm}^{2}$ to $2 \times 2 \mu \mathrm{m}^{2}$. Sets of AFM images were analyzed by surface grain extraction, from which the surface grain size and distribution were obtained. In addition, a set of pm$\mathrm{Si}: \mathrm{H}$ PIN layer stacks co-deposited on various substrates such as Corning Eagle glass, textured $\mathrm{SnO}_{2}: \mathrm{F}$ (Asahi-U), and flat $\mathrm{ZnO}: \mathrm{Al}$, was light-soaked for longer periods (up to $100 \mathrm{~h}$ under $100 \mathrm{~mW} / \mathrm{cm}^{2}$ ) and the changes in their topology were characterized by scanning electron microscopy (SEM) and atomic force microscopy (AFM). Veeco's Dimension 5000 was used for AFM, and Hitachi 4800 was used for SEM.

Another important feature in the evolution of film and device properties under light-soaking is the behavior of the hydrogen they contain. To study the characteristics of Si-H bond breaking and subsequent dangling bond recombination as a consequence of light-soaking, infrared absorption was measured for both a-Si:H and pm-Si:H solar cells. Infrared spectra in transmission mode were measured with a Nicolet 6700 Fourier transform infrared spectrometer on samples grown on $\langle 100\rangle$ highly resistive $\left(>10^{4} \Omega \mathrm{cm}\right) \mathrm{FZ}$ c-Si substrates. Its resolution was set to $4 \mathrm{~cm}^{-1}$. The transmission spectra, resulting from the average over 32 scans, were normalized to the transmission of the c-Si substrates. As a complementary study for infrared absorption, hydrogen exodiffusion experiments were performed on pm-Si:H PIN stacks. During these experiments, the base vacuum was $10^{-7}$ mbar and the heating rate was $10^{\circ} \mathrm{C} / \mathrm{min}$. The effused hydrogen was detected by a quadruple mass spectrometer (QMS), and recorded in a continuous manner with the increase in temperature, to obtain the hydrogen exodiffusion spectrum. For this study, a pm-Si:H PIN solar cell was prepared on Corning Eagle glass substrate and then cut into three pieces: one as a control, a second one light-soaked for one hour, and a third one light-soaked for $20 \mathrm{~h}$. 
K.H. Kim et al.: Light induced electrical and macroscopic changes in hydrogenated polymorphous silicon solar cells

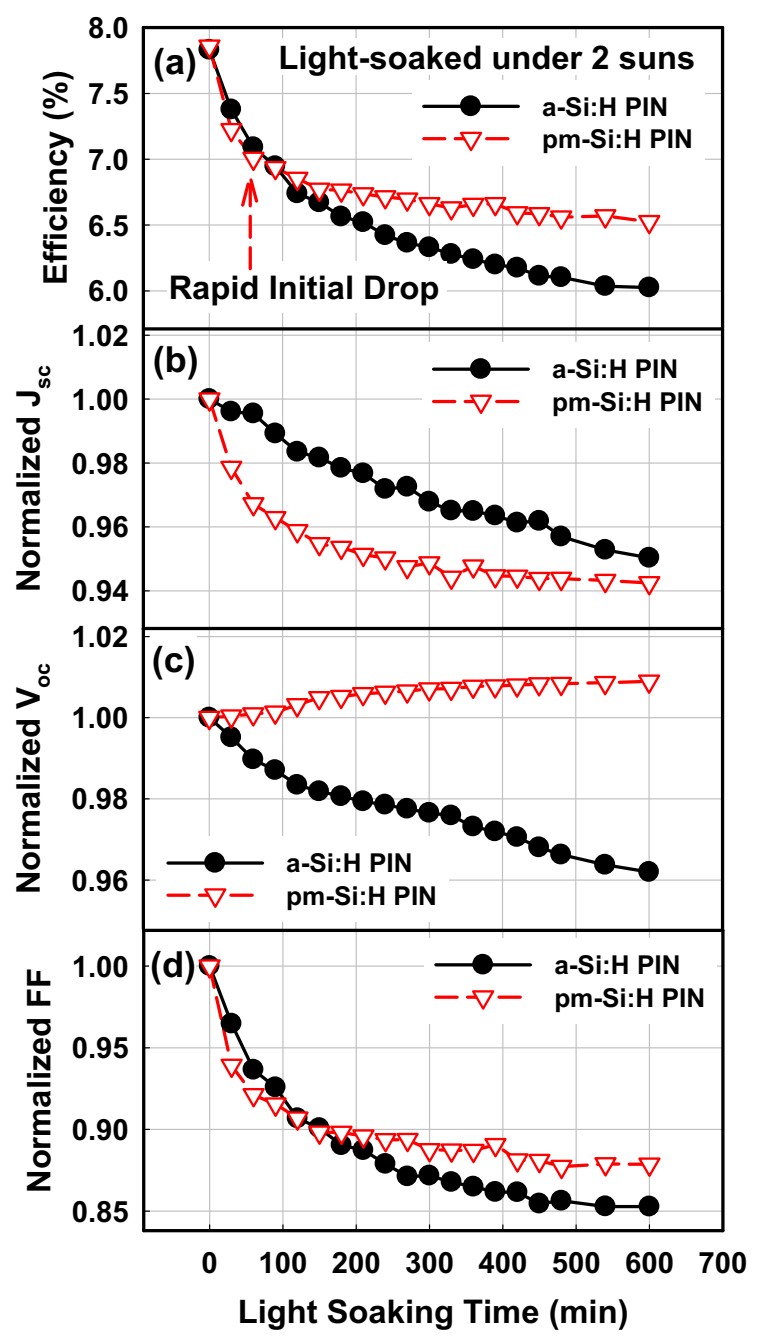

Fig. 1. Evolution of a-Si:H and pm-Si:H PIN solar cell (a) power conversion efficiency (b) normalized $J_{s c}$ (c) normalized $V_{o c}$ and (d) normalized Fill Factor during light-soaking under an illumination of $200 \mathrm{~mW} / \mathrm{cm}^{2}$.

To characterize the variations in the material properties during light-soaking, spectroscopic ellipsometry was performed on a pm-Si:H PIN solar cell deposited on flat glass. The cell was light-soaked for $200 \mathrm{~min}$ and five SE spectra were taken during this period. The resulting spectra were modeled using the Tauc-Lorentz dispersion model and the material parameters were obtained from the modeling [7].

\section{Results}

\subsection{Evolution of the solar cell parameters as a function of light-soaking time}

Figure 1 shows the power conversion efficiency, normalized $J_{s c}$, normalized $V_{o c}$ and normalized Fill Factor of PIN solar cells as a function of light-soaking time. One can see a clear difference in the light-induced degradation behavior of the pm-Si:H and the a-Si:H PIN solar cells. The conversion efficiency behavior shows that the pm-Si:H solar cell is more stable than that having a-Si:H as intrinsic layer. However, the pm-Si:H solar cell shows a rapid efficiency drop at the early stages (about first two hours) of lightsoaking. The $J_{s c}$ of the pm-Si:H solar cell (Fig. 1b) shows a faster initial drop followed by a phase of more moderate degradation at longer light-soaking times, while the a-Si:H solar cell demonstrates a monotonic degradation and no clear distinction into such "phases". The faster initial decrease of $J_{s c}$ is the major contribution to the initial efficiency degradation of pm-Si:H solar cell, and it differs in character from the classic stretched exponential behavior observed in a-Si:H. The difference in behavior between the two types of cells is also striking for $V_{o c}$ (Fig. 1c), which increases for the pm-Si:H cell, whereas it drops for the a$\mathrm{Si}: H$ solar cell during light-soaking. This behavior cannot be explained by heating of the cells. Indeed if this were the case, then we should observe a decrease in $V_{o c}$ and an increase in $J_{s c}$. Therefore, the increase of $V_{o c}$ provides a strong indication that heating effects are negligible during light-soaking, in agreement with the Pt-100 thermoresister probe measurement indicating that the temperature of the PIN solar cells stayed under $50{ }^{\circ} \mathrm{C}$ during light-soaking. It is important to note that the data in Figure 1 were continuously recorded during the light-soaking, without turning off the lamp. Further results on the irreversibility of pm-Si:H solar cells characteristics will be presented in a forthcoming publication.

Various hypothesis have been proposed to explain the increase in $V_{o c}$ : (i) the activation of boron in the $p$-layer of the solar cells during light-soaking [4,13-18], (ii) light-induced changes in the intrinsic mixed-phase material [19-21] and (iii) decrease in valence band tail and state re-distribution at $p / i$ interface [22]. Most of those studies deal with solar cells based on a-Si:H materials deposited by dissociating silane-hydrogen gas mixtures, while our standard a-Si:H was deposited by dissociating pure silane. Therefore, the physical origin of the $V_{o c}$ kinetics of the a$\mathrm{Si}: \mathrm{H}$ solar cells in the literature can differ from that of our standard a-Si:H PIN solar cells. Besides, common physical origin in the discussion of the $V_{o c}$ increase is hydrogen motion, and it is rather related to the highly hydrogen diluted silane gas mixture of pm-Si:H deposition. Another interesting point on the $V_{o c}$ increase in the literature is that none of those studies addressed comprehensive study with kinetics of $J_{s c}$. It has also been reported that a$\mathrm{Si}: H$ shows very fast creation of charged gap states during light-soaking which could be related to the fast degradation kinetics of the pm-Si:H cell [23], but midgap state creation should lead to a decrease in $V_{o c}$ in addition to that of the overall efficiency. Therefore, we consider that fast state creation is insufficient for the explanation behind the particular degradation of pm-Si:H solar cells and that other phenomena must be involved. To better understand the light-induced changes reported in Figure 1, a set of complementary techniques was used to characterize the changes in the structure of the films during or after light-soaking. 

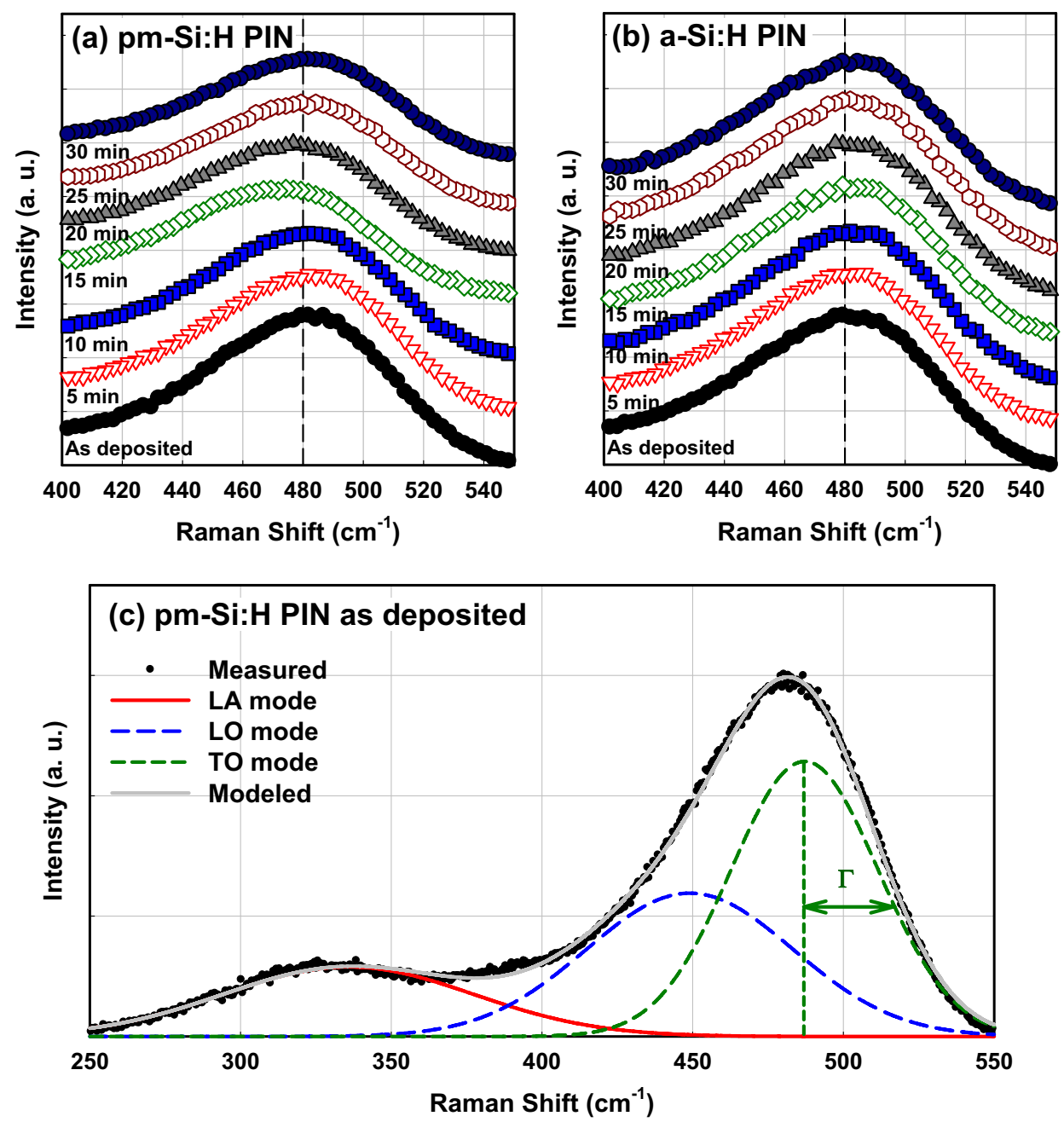

Fig. 2. Raman spectra evolution during light-soaking (LS) of (a) pm-Si:H, (b) a-Si:H PIN solar cells and (c) Raman spectrum of as-deposited pm-Si:H PIN solar cell and its deconvolution. Note that spectra evolution data are presented for LS times up to $30 \mathrm{~min}$.

\subsection{In-situ Raman studies}

Figures $2 \mathrm{a}$ and $2 \mathrm{~b}$ show the evolution during lightsoaking of the Raman spectra of the a-Si:H and pm-Si:H PIN stacks on glass, for which the spectra have been normalized to the intensity of the TO mode. In contrast with a-Si:H PIN stack, the Raman spectra of the pm-Si:H PIN displays a peak shift during light-soaking, as well as a small broadening, and these two changes were observed in multiple samples. To quantify these changes, TO peak position and RMS bond angle deviation, $\delta \theta$, were determined through deconvolution of the measured spectra. Figure $2 \mathrm{c}$ shows the Raman spectrum of as-deposited pm-Si:H PIN stack and its deconvolution. The Raman spectra of both pm-Si:H and a-Si:H consist of a broad peak located at around $480 \mathrm{~cm}^{-1}$, which corresponds to the TO mode in the amorphous phase, and the LO and LA modes are additionally observed at lower wave numbers around $330 \mathrm{~cm}^{-1}$ and $440 \mathrm{~cm}^{-1}$, respectively $[24-26]$.

The half width of the TO band $(\Gamma)$ is a sensitive measure of local disorder, and correlates with rms deviations in the bond angle $(\delta \theta)$ from the ideal tetrahedral bond angle of $109.4^{\circ}$. The shift of the peak position can be treated as a measure of the average strain resulting from built in stress. To minimize the influence of the weak vibrational modes, LA and LO, one can perform a best fit on each spectrum from 250 to $550 \mathrm{~cm}^{-1}$ by three Gaussian curves and a straight base line [24]. The RMS bond angle deviation was deduced using the following formula, proposed by Beeman et al. [27, 28].

$$
\Gamma=15+6 \delta \theta \text {. }
$$

Figure 3 shows the TO peak position and $\delta \theta$ change during light-soaking. One can clearly see that the TO peak of pm-Si:H PIN shifts towards lower wavenumbers during light-soaking, whereas the two a-Si:H PINs show no change. Since the shift of the Raman peak towards lower wavenumbers could be due to local heating from laser excitation, the pm-Si:H PIN was allowed to cool in the dark for 20 min after light-soaking. However, the peak position remained same, as shown in Figure 3a. Physically, a phonon is a quantized mode of vibration occurring in a 


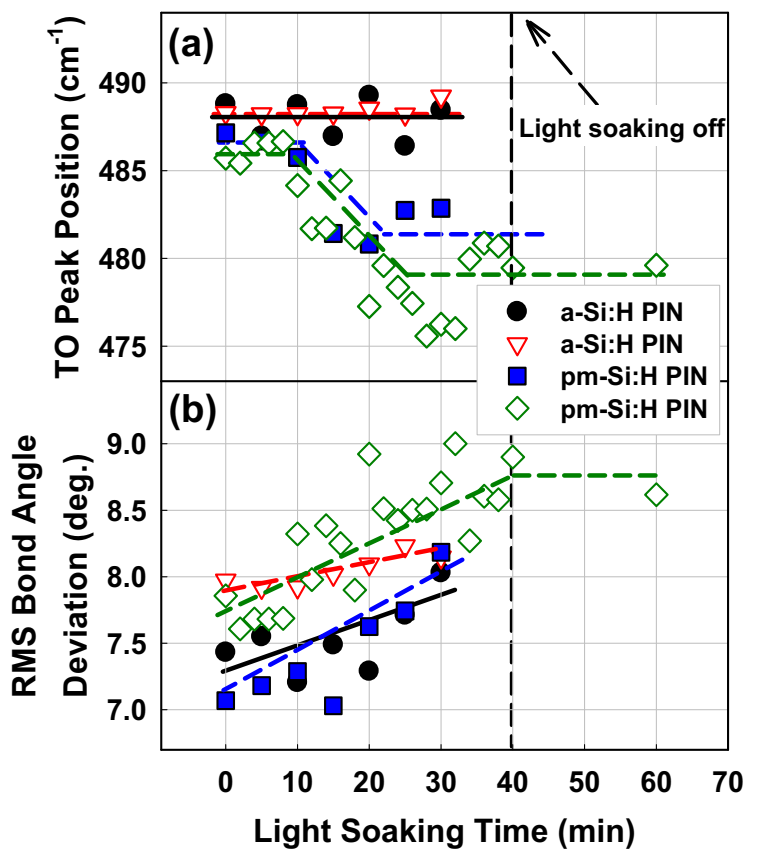

Fig. 3. Evolution of (a) TO peak position and (b) RMS bond angle deviation as deduced from Raman scattering measurements during light-soaking. On some samples we have checked that these material properties did not change after turning off the light.

rigid crystal lattice, such as the atomic lattice of a solid. The Raman spectra peak shift towards lower $k$ can be regarded as a consequence of increasing the inter-atomic distance, that is, tensile stress. On the other hand, it should be noted that for all the samples, the TO band position in the as-deposited state is above at $480 \mathrm{~cm}^{-1}$ which can be related to compressive stress in the as-deposited films. However, while the peak position does not change for the a-Si:H PIN stack, it shifts to low wavenumbers for the pm$\mathrm{Si}: \mathrm{H}$ case during light-soaking. It can therefore be stated that the cells are under high compressive stress, as is usually the case for plasma deposited silicon thin films [29]. In other words, the peak position evolution from higher $k$ to lower $k$ (towards $480 \mathrm{~cm}^{-1}$ ) suggests a relaxation of compressive stress during light-soaking for the pm-Si:H films.

\subsection{In-situ AFM studies}

Figures $4 \mathrm{a}-4 \mathrm{~d}$ show examples of AFM images taken in both the as-deposited and light-soaked states for both a-Si:H and pm-Si:H PIN stacks on glass. For both a-Si:H and pm-Si:H PIN layer stacks we observe a grain structure related to the surface roughness of the samples. Indeed, based on the Raman spectra shown in Figure 2, the grains are amorphous. The Watershed image processing segmentation algorithm was used to extract information about the surface grain area $[30,31]$ by splitting the images into grains, based on the topology of the image. Figure $4 \mathrm{e}$ summarizes the surface grain size change during
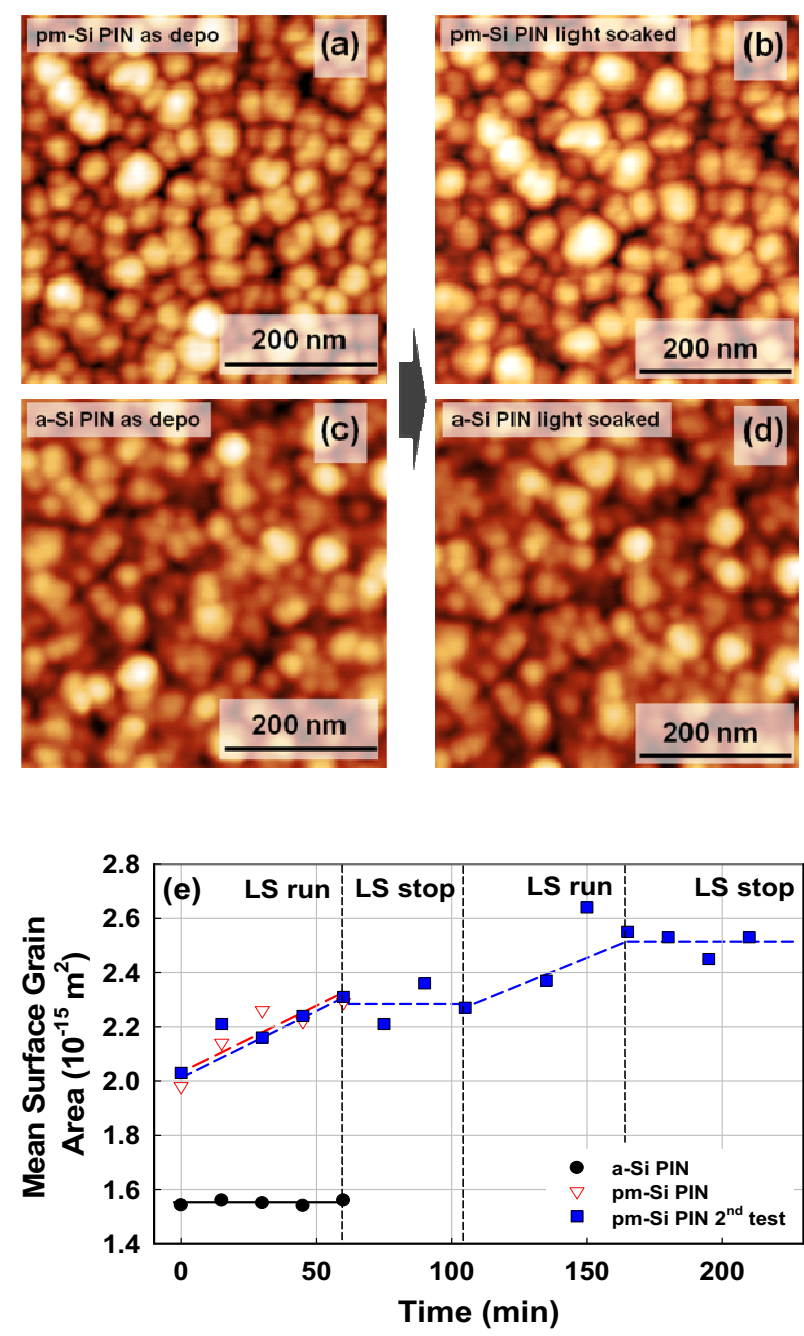

Fig. 4. AFM images of pm-Si:H and a-Si:H solar cells on Corning Eagle glass before (a, c) and after (b, d) light-soaking, and (e) mean surface grain area evolution during light-soaking, as extracted from AFM images. Note that no evolution is observed for the a-Si:H film, and that the evolution for the pm$\mathrm{Si}: \mathrm{H}$ cell stops when the light source is off.

light-soaking analyzed from surface grain extraction. One can see that the surface grain area of pm-Si:H PIN increases as a function of light-soaking time, and this expansion stops if light-soaking is stopped, which is to say that the surface expands while light-soaking occurs, and it remains expanded once light-soaking stops. For the a-Si:H PIN, no significant change was observed. As in the case of the Raman measurements, these results were reproduced in multiple trials.

To eliminate the effect of image drift on the AFM scan during light-soaking, individual grain sampling was performed on a selected set of grains. As shown in Figure 5a, a region was first chosen from the AFM images that remained within the field of measurement during the lightsoaking, and eight surface-grains from within that region were analyzed. The surface of each grain was extracted by the Watershed algorithm. Figure 5a shows an example 
(a)
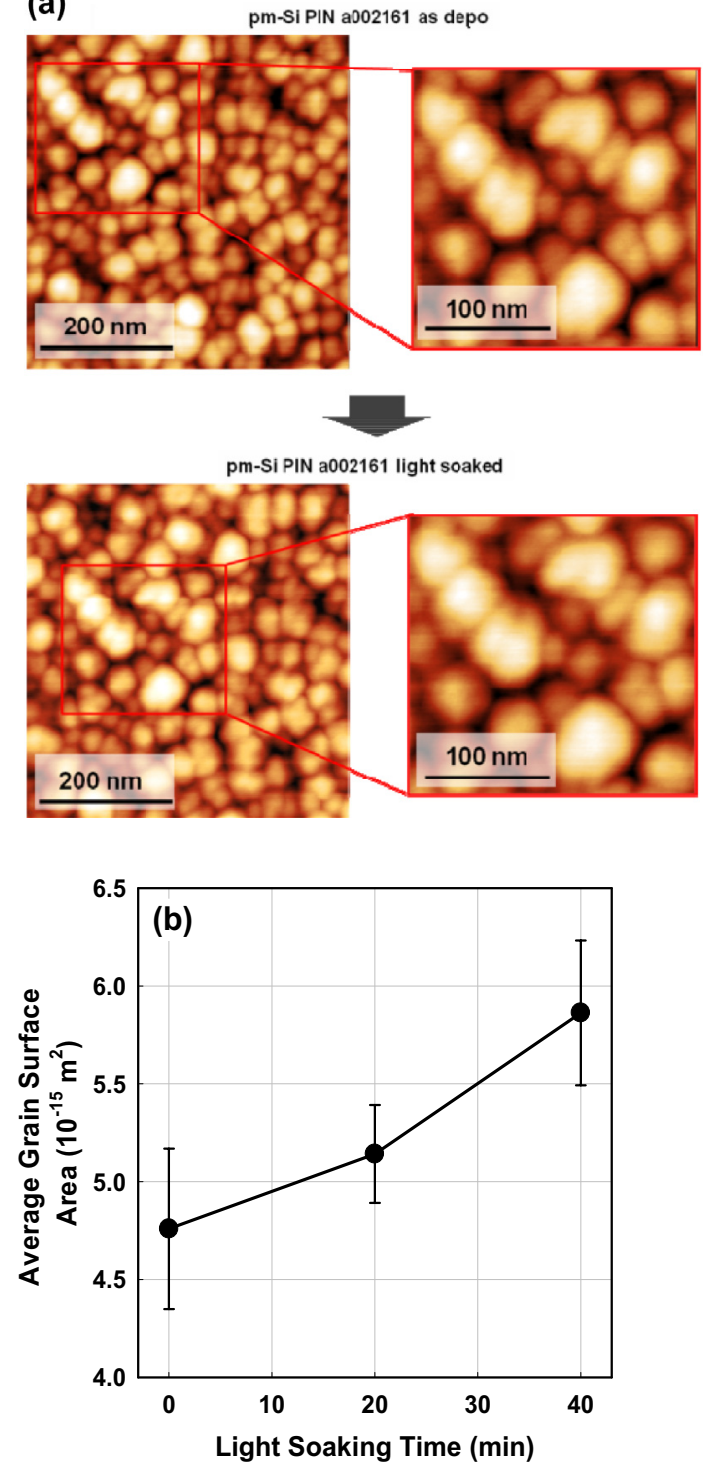

Fig. 5. (a) Demonstration of zone selection for AFM images to follow changes in area of individual grains, and (b) average surface area evolution of selected grains during light-soaking of pm-Si:H film.

from cropping a sample region, and Figure $5 \mathrm{~b}$ shows the average area of the eight selected grains as a function of light-soaking time. In spite of the small sample size, the manual grain extraction shows the same trend as the statistical group behavior of surface grains in Figure 4e. Therefore, one can conclude that the "swelling" behavior of the surface grains is not due to an image drift effect, but due to light-soaking induced changes on the thin film topology.

\subsection{Infrared absorption studies}

Figure 6 shows the absorbance spectra in the stretching region of a-Si:H and pm-Si:H PIN stacks on FZ
c-Si substrates extracted from infrared transmission. The stretching region of infrared absorption consists of two peaks centered at $2000 \mathrm{~cm}^{-1}$ and $2090 \mathrm{~cm}^{-1}$ [32]. The $2000 \mathrm{~cm}^{-1}$ mode is commonly associated with isolated $\mathrm{Si}-\mathrm{H}$ groups in the bulk, related to the saturation of the dangling bonds during growth [33], while the $2090 \mathrm{~cm}^{-1}$ mode is attributed to clustered monohydrides and/or dihydrides. Furthermore, there is a third peak, which is detected in pm-Si:H PIN samples, centered at around $2030 \mathrm{~cm}^{-1}$. The stretching mode at $2030 \mathrm{~cm}^{-1}$ has been interpreted as clustered $\mathrm{Si}-\mathrm{H}$ groups in the form of platelet-like configurations [34]. Therefore, this component could come from $\mathrm{Si}-\mathrm{H}$ bonds at the amorphouscrystalline interface at nanocrystals surface in pm-Si:H.

Infrared absorption behavior during light-soaking is quite distinct for those two materials. a-Si:H PIN shows slow but steady reduction of its stretching modes absorbance during light-soaking. It is believed that $\mathrm{Si}-\mathrm{H}$ bonds are broken under illumination, creating dangling bonds. However, in pm-Si:H PIN case, there is an increase in its stretching modes absorption at the early stages (up to five hours) of light-soaking. The absorption starts to decrease after light-soaking for $20 \mathrm{~h}$, but the absorption is still higher than as-deposited state. The result shows a good agreement with literature [35]. Few more tests were done for the reproducibility, and the initial absorption increase was found to be reproducible. Multiple infrared transmission spectra were taken to check the error range, which was found to be in $\pm 0.1 \%$ of its absolute transmission. Thus the error range is much lower than the change in transmission caused by light-soaking, which is more than $\pm 0.5 \%$. Therefore, one can conclude that there is very small change in total amount of $\mathrm{Si}-\mathrm{H}$ bonds, both in a-Si:H and pm-Si:H PIN layer stacks, but there is reproducible consistency in their behavior. That is, initial increase of infrared absorption band of pm-Si:H PIN layer stack contrary to a-Si:H, which shows monotonous decrease.

\subsection{Hydrogen exodiffusion studies}

Figure 7 shows the $\mathrm{H}_{2}$ partial pressure detected during exodiffusion, normalized to the volume of the sample, as a function of temperature of pm-Si:H PIN layer stack on glass. The exodiffusion spectrum of the as-deposited pm-Si PIN shows two distinct peaks at around $350{ }^{\circ} \mathrm{C}$ and $500{ }^{\circ} \mathrm{C}$ along with hydrogen spikes at low temperature around $250{ }^{\circ} \mathrm{C}$. The peak at $350{ }^{\circ} \mathrm{C}$ is associated with the presence of weakly bonded hydrogen, which characterizes pm-Si:H $[34,36]$, or it is also considered to be molecular hydrogen in the material $[37,38]$. At $500{ }^{\circ} \mathrm{C}$, hydrogen from isolated $\mathrm{Si}-\mathrm{H}$ bonds effuses, leaving behind dangling bonds [39]. In addition, it should be noted that the low temperature peak at $350{ }^{\circ} \mathrm{C}$ can be also come from the fact that we are analyzing a PIN stack instead of just an intrinsic layer. As a matter of fact, it has been shown that there is a quite different effusion behavior between $p / i$ and $n / i$ layer stacks. The $p / i$ structure shows the low temperature effusion peak at $300{ }^{\circ} \mathrm{C}$, while $n / i$ 

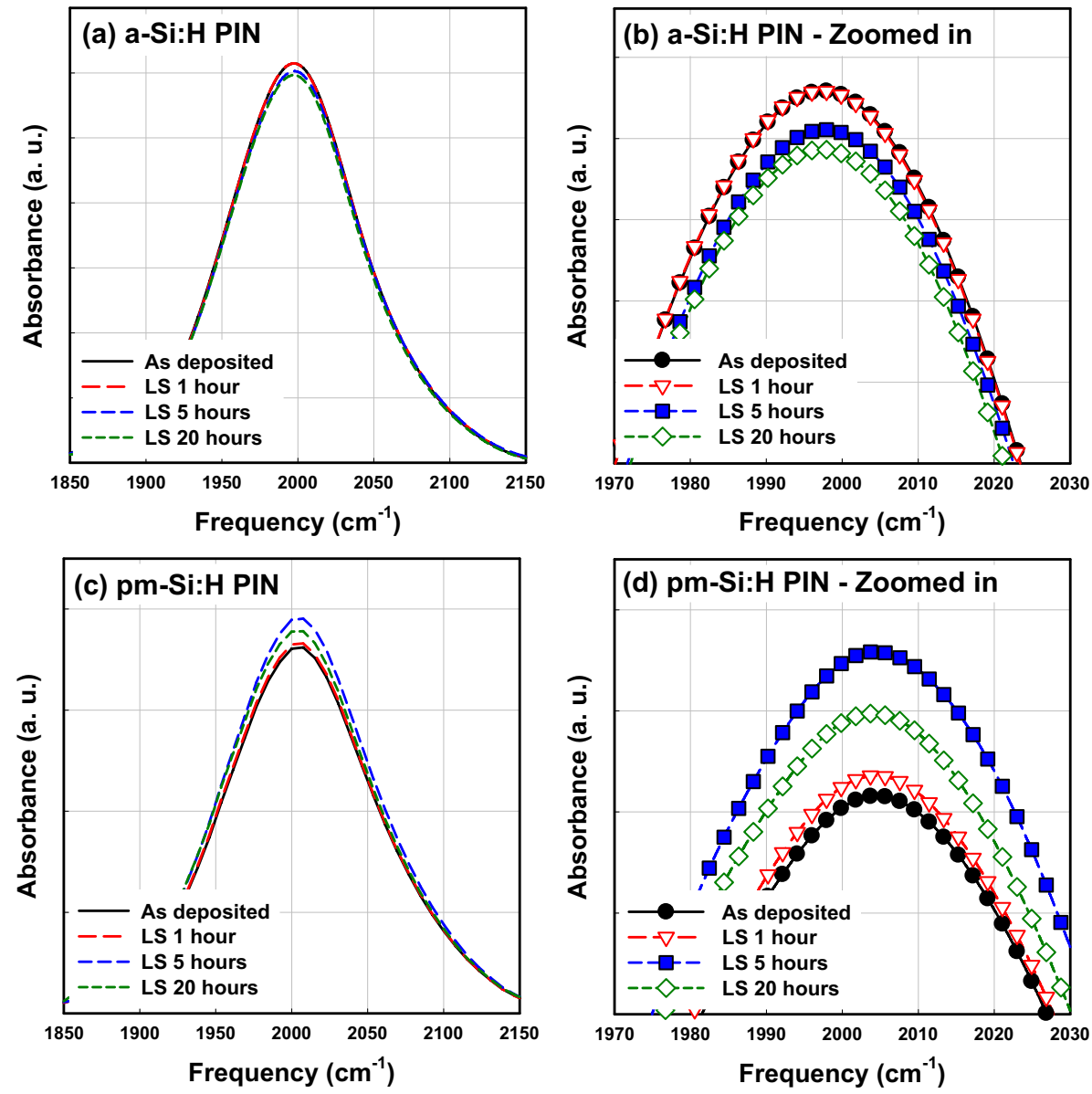

Fig. 6. Absorbance spectra of stretching modes of (a) a-Si:H and (c) pm-Si:H PIN layer stacks on intrinsic FZ wafer and their zoom-in to the peak $(b, d)$. The spectra are extracted from infrared transmission at four light-soaking (LS) states : as-deposited (black), after one hour of LS (red), after $5 \mathrm{~h}$ (blue) and after $20 \mathrm{~h}$ (green).

structure shows shift of the effusion peak to higher temperature of $450{ }^{\circ} \mathrm{C}$ [40]. There are few possible reasons to have a low temperature peak in the structure with $p$ layer at bottom. Boron doped a-SiC:H layers are porous, and have a high diffusion coefficient of hydrogen [41], so atomic hydrogen could incorporate if another layer is deposited on top of the boron doped a-SiC:H layer. Therefore, molecular hydrogen could already exist in $p$-layer or $p$-layer/substrate interface. More detailed comprehensive view with the other results will be dealt in the discussion section.

The most striking result in Figure 7 is that the peak at $350{ }^{\circ} \mathrm{C}$ disappeared after light-soaking for one hour. This change is reproducible and is also observed on the sample light-soaked for $20 \mathrm{~h}$. It is in fact surprising because not only the change is very abrupt, but also such change is much stronger than the change in infrared absorption study in previous section. Reminding that only bonded hydrogen is detected by infrared spectroscopy, the origin of the peak at $350{ }^{\circ} \mathrm{C}$ should be molecular hydrogen in microvoids or at $p$-layer/substrate interface. Furthermore, the signal at $400{ }^{\circ} \mathrm{C}$ increased after light-soaking. It is considered to be related to the initial increase of stretching modes absorbance in previous section (Fig. 6). It implies

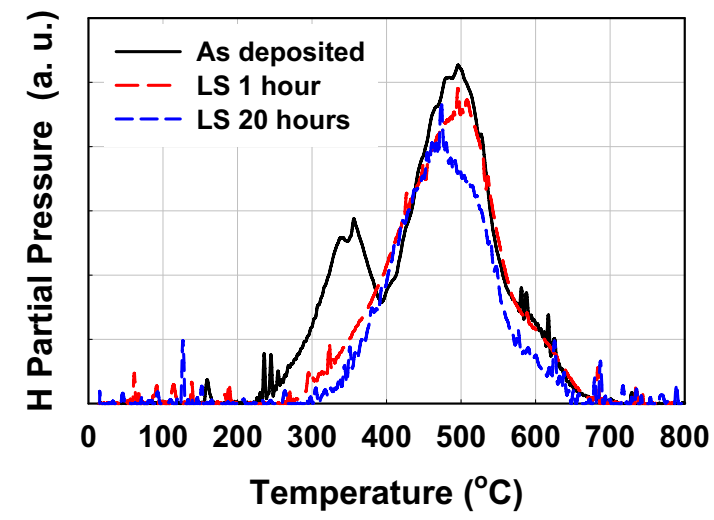

Fig. 7. Hydrogen exodiffusion results of co-deposited pm-Si:H PIN solar cells for three light-soaking (LS) states : as-deposited (black), after one hour of LS (red), and after $20 \mathrm{~h}$ (blue). Note the disappearance of the peaks around $350{ }^{\circ} \mathrm{C}$ even after $1 \mathrm{~h}$ of LS.

that a portion of molecular hydrogen in $350{ }^{\circ} \mathrm{C}$ peak may have converted into bonded hydrogen. After light-soaking for $20 \mathrm{~h}$, the signal at $400{ }^{\circ} \mathrm{C}$ is still higher than its initial value, even if the high temperature signal $\left(\sim 500^{\circ} \mathrm{C}\right)$ shows 

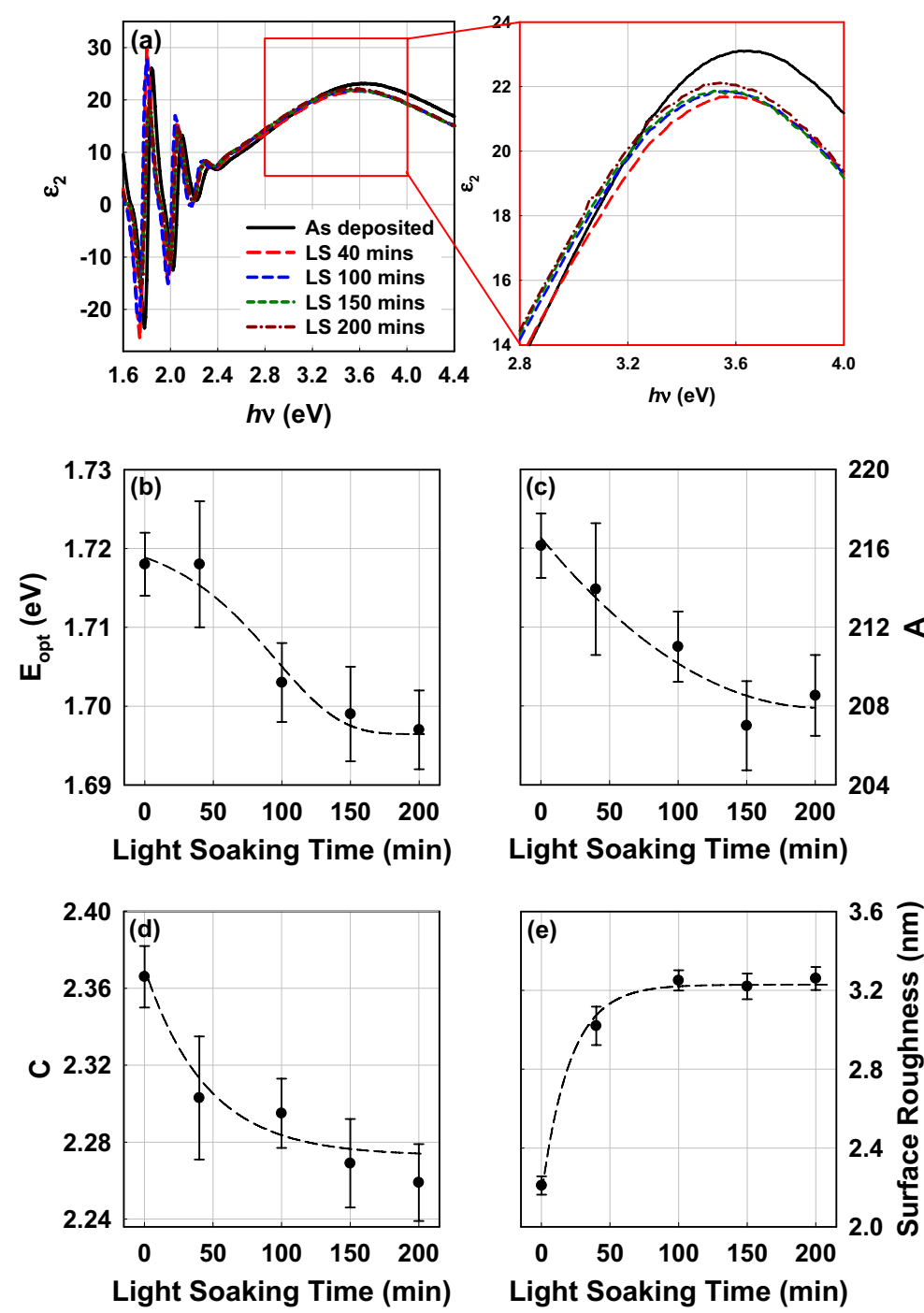

Fig. 8. Evolution of (a) pseudo-dielectric function of a pm-Si:H PIN layer stack on Corning Eagle glass at various stages of light-soaking, as measured by spectroscopic ellipsometry, and of material parameters as extracted from the measured spectra: (b) optical bandgap $E_{\text {opt }}$, (c) density parameter $A$, (d) disorder parameter $C$, and (e) surface roughness.

obvious reduction. In order to have more detailed information, the exodiffusion results were deconvoluted into five Gaussian peaks, and the results of such analysis are summarized in Table 1 . The exodiffusion result of the asdeposited sample is characterized by five peaks at $320^{\circ} \mathrm{C}$, $353{ }^{\circ} \mathrm{C}, 469{ }^{\circ} \mathrm{C}, 516{ }^{\circ} \mathrm{C}$ and $591{ }^{\circ} \mathrm{C}$. Note that the spikes were not taken into account in the deconvolution. Table 1 shows that the area of the peak at $460{ }^{\circ} \mathrm{C}$ increased after light-soaking for one hour, while the two low temperature peaks $\left(320,353{ }^{\circ} \mathrm{C}\right)$ disappeared. This gives support to the fact there is not only diffusion of molecular hydrogen, but also reconstruction of $\mathrm{Si}-\mathrm{H}$ bonding during light-soaking [36], and molecular hydrogen should play an important role in this process [42].

Last but not least, unusual sharp spikes are observed at low temperature (as low as $50{ }^{\circ} \mathrm{C}$ ) for the light-soaked samples. The detection of these low temperature spikes in the light-soaked samples suggests that a portion of molec- ular hydrogen $\left(350^{\circ} \mathrm{C}\right.$ peak $)$ is also transformed to be mobile during the light-soaking and accumulates at internal cavities or at the film/substrate interface. This hydrogen can easily escape during macroscopic cracking events and introduce sharp and rapid increases in hydrogen partial pressure at even lower temperature than $350{ }^{\circ} \mathrm{C}$ in the exodiffusion experiments [37].

\subsection{Spectroscopic ellipsometry studies}

Figure 8 shows the imaginary part of the pseudodielectric function of the film measured by spectroscopic ellipsometry, as well as the material parameters deduced from modeling the pm-Si:H PIN stack on glass. Let us recall that $E_{\text {opt }}$ is the optical bandgap, whereas $A$ and $C$ are parameters related to the density and the disorder, respectively $[7,43]$. It is interesting to note that most of 
K.H. Kim et al.: Light induced electrical and macroscopic changes in hydrogenated polymorphous silicon solar cells

Table 1. Peak positions and integrated areas extracted from exodiffusion results of Figure 6. Data are presented for co-deposited pm-Si:H cell layer stacks after three light-soaking conditions (as-deposited, $1 \mathrm{~h}$, and $20 \mathrm{~h}$ ).

\begin{tabular}{cccccc}
\hline \multicolumn{2}{c}{ As-deposited } & \multicolumn{2}{c}{ Light-soaked $1 \mathrm{~h}$} & \multicolumn{2}{c}{ Light-soaked $20 \mathrm{~h}$} \\
\hline Peak position $\left({ }^{\circ} \mathrm{C}\right)$ & Area (a.u.) & Peak position $\left({ }^{\circ} \mathrm{C}\right)$ & Area (a.u.) & Peak position $\left({ }^{\circ} \mathrm{C}\right)$ & Area (a.u.) \\
\hline 320 & 2.43 & & & & \\
353 & 2.32 & & & & \\
469 & 9.06 & 464 & 12.1 & 557 & 9.44 \\
516 & 2.99 & 507 & 2.59 & 509 & 1.98 \\
590 & 2.23 & 596 & 1.18 & 584 & 1.35 \\
Total & 19.03 & & 15.87 & & 12.77 \\
\hline
\end{tabular}

the changes occur during the initial stages of light-soaking, especially during first $100 \mathrm{~min}$. The zoom of the high energy part of the ellipsometry spectra (Fig. 8a) shows that during the first $40 \mathrm{~min}$ of light-soaking there is a strong decrease in the amplitude of $\varepsilon_{2}$, which can be accounted by an increase of the surface roughness of the films (see Fig. 8e), consistent with published results [44] and AFM images (Figs. 4 and 5). At longer times, lightsoaking mainly results in a shift of the absorption edge (low energy part in the zoom of $\varepsilon_{2}$ ) to lower energy. This shift is associated with the decrease of the $E_{\text {opt }}$ (Fig. $8 \mathrm{~b}$ ). There are two possible reasons for the decrease in $E_{\text {opt }}$. It could refer that $\mathrm{Si}-\mathrm{H}$ is breaking as a consequence of lightsoaking, even if our infrared spectroscopy shows initial increase of Si-H bonding absorption, yet $E_{\text {opt }}$ showed a bit delayed decrease comparing to the other material parameters. The other reason can be the inter-atomic distance. In-situ Raman and AFM revealed that light-soaking introduces stress-relaxation, which also implies that interatomic distance gets larger after light-soaking. Less splitting of orbital energy (band gap) is then expected from larger inter-nuclear distance of atoms. Decrease of the density parameter $A$ suggests that the sample is getting more porous. Such porosity could connect the stress relaxation detected by Raman and AFM measurement to the hydrogen cavity formation in exodiffusion study (sharp low temperature peaks). Furthermore, increase in surface roughness could be also connected to the macroscopic change observed by AFM.

\subsection{Long term changes in surface morphology for stacks on transparent conductive oxides}

In the previous sections, changes in film morphology during light-soaking were observed for the films deposited on glass or crystalline silicon wafer. We turn now to lightsoaking effects on the same PIN layer stacks deposited on transparent conductive oxide substrates. Figure 9 shows SEM and AFM images of the surface of pm-Si:H PINs on flat $\mathrm{ZnO}: \mathrm{Al}$ both before and after light-soaking for $16 \mathrm{~h}$. Images throughout the entire $1 \times 1$ square inch substrate were acquired on the as-deposited state and after light-soaking. While the as-deposited sample shows no clear feature except surface roughness (Fig. 9a), the light-soaked sample shows that the surface morphology is strongly modified (Fig. 9b). A large number of both dark
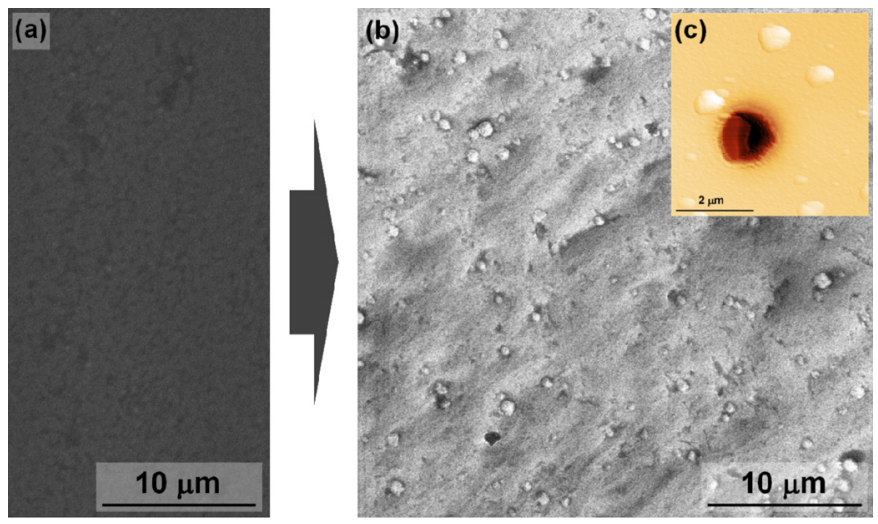

Fig. 9. SEM images of pm-Si:H PIN solar cell surface when deposited on flat $\mathrm{ZnO}: \mathrm{Al}$ : (a) as-deposited, and (b) light-soaked (LS) for $16 \mathrm{~h}$. (inset, c) AFM image of surface shown in (b).

objects and mound-like objects is observed and the formation of holes takes place all over the surface. The depth of the holes and height of the mounds are estimated from the cross section of the AFM images (Fig. 9c). The depth of the holes varies from 30 to $400 \mathrm{~nm}$, which means that some of the holes correspond to a complete peeling off of the pm-Si:H PIN layer. The height of the mound-like objects is of the order of about $100 \mathrm{~nm}$. For the mound like objects, it is clear that they are not dust or particles because of their surface topology is similar to that of the rest of the surface, as well as the fact that they are not seen in the as-deposited state. In addition, not only circular shaped holes, but also many irregular shaped holes are found in SEM images. It implies that the macroscopic changes are similar to the buckling observed when films are annealed at high temperature [34, 40, 45, 46].

Because the above results could be due to the use of flat $\mathrm{ZnO}: \mathrm{Al}$, we performed another light-soaking test on a pm-Si:H PIN layer stack deposited on a textured Asahi $\left(\mathrm{SnO}_{2}: \mathrm{F}\right)$ substrate, which is usually used for PIN solar cells. The PIN layer stack was light-soaked for 100 hours, and again many irregularly shaped large holes were found. Figure 10 shows an AFM image of one of these holes. One can see that the size of the hole is larger $(\sim 20 \mu \mathrm{m})$ than the ones in Figure 9 ( few $\mu \mathrm{m})$, and its depth corresponds to the film thickness (about $400 \mathrm{~nm}$ ), suggesting that the film has completely peeled off. Furthermore, many small sized holes $(\sim$ few $\mu \mathrm{m})$ are also seen in Figure 10 , similar to those observed on flat $\mathrm{ZnO}: \mathrm{Al}$ (Fig. 9b). As mentioned 

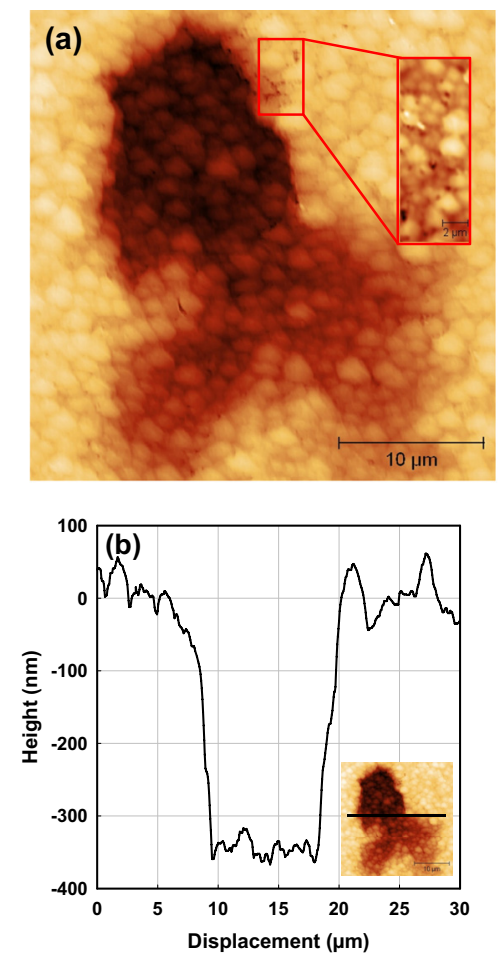

Fig. 10. (a) AFM image of a pm-Si:H PIN on textured Asahi substrate after $100 \mathrm{~h}$ of light-soaking and (b) cross-sectional profile measurement through center of hole showing a depth of almost $400 \mathrm{~nm}$.

in the paragraph above, it is believed that the formation of those irregular shaped holes and mounds is linked to the relaxation of the high compressive stress in the asdeposited films.

\section{Discussion}

With the experimental results presented above, we now aim to understand the particular evolution of the pm-Si:H solar cell parameters $\left(V_{o c}, J_{s c}\right)$ shown in Figure 1. In-situ Raman and AFM measurements reveal that light-soaking plastically relaxes mechanical stress. Light-soaking also introduces large structural changes resulting in the diffusion of molecular hydrogen, as deduced from infrared absorption, exodiffusion and spectroscopic ellipsometry studies. For a long exposure time, light-soaking leads to the formation of holes - where the film completely peels off - and mounds, which form with a height up to half of the film thickness.

One could argue that the presented results can be led by illumination induced local heating. However, three observations suggest this is not the case. First, heating of the PIN solar cells by illumination was suppressed by fan cooling. As mentioned above, the temperature stayed under $50{ }^{\circ} \mathrm{C}$ even at 2 suns of illumination (well below the deposition temperature of $175^{\circ} \mathrm{C}$ ). Second, we have observed increasing $V_{o c}$ and decreasing $J_{s c}$. The opposite would be seen if pm-Si:H cells were heated. At last, Raman measurements show that the TO peak remained in same position even after cooling down for $20 \mathrm{~min}$. Therefore, we conclude that the macroscopic changes presented here do not rely on heating, but on illumination.

Based on our experimental study, the collected results can be summarized as follows:

1. Light-soaking introduces a fast decrease in $J_{s c}$ and an increase of $V_{o c}$ on pm-Si:H PIN solar cells (Fig. 1).

2. In-situ Raman measurements (Figs. 2 and 3) reveal that light-soaking relaxes the compressive stress in the as-deposited pm-Si:H PIN, and such relaxation is connected to surface expansion as detected by in-situ AFM measurements (Figs. 4 and 5).

3. Infrared absorption and exodiffusion studies (Figs. 6 and 7) demonstrate that light-soaking induces strong changes on the hydrogen distribution in the material. In particular, the disappearance of the exodiffusion peak at $350{ }^{\circ} \mathrm{C}$, the increase in infrared stretching modes absorbance, as well as the increase in the exodiffusion signal at $400{ }^{\circ} \mathrm{C}$ and the arise of low temperature sharp spikes after light-soaking. These results suggest that molecular hydrogen in the pm-Si:H PIN stack $\left(350{ }^{\circ} \mathrm{C}\right.$ peak in exodiffusion) effuses out during light-soaking, and a portion of the effused hydrogen is converted into bonded hydrogen and into hydrogen filled cavities, in particular at the substrate $/ p$-layer interface.

4. Spectroscopic ellipsometry studies (Fig. 8) also provide evidence of macroscopic changes of pm-Si:H PIN solar cell through the evolution of the density parameter A and the increase of surface roughness.

5. The SEM and AFM results (Figs. 9 and 10) reveal visible macroscopic changes due to light-soaking, which manifest through the formation of macroscopic holes and mounds.

These results lead us to postulate that light-soaking leads molecular hydrogen to effuse from pm-Si:H PIN solar cell, and a fraction of molecular hydrogen (made mobile during light-soaking) forms cavities, probably around the silicon nanocrystals of the pm-Si:H material and at the substrate/ $p$-layer interface. This causes the mounding and peeling behavior observed in the microscope images. Therefore, the question is whether there is a connection between the macroscopic changes and the behavior of the solar cell parameters.

Indeed, there is a general consensus on light-soaking modifying hydrogen incorporations in a-Si:H. Lightinduced, long-range $\mathrm{H}$ motion has been postulated as the key step in the Branz model of SWE defect formation $[47,48]$. According to the Branz model, only a small subset of the Si-H bonds involved in the SWE contributes to metastable dangling bond formation, while most of the broken Si-H bonds are recycled by re-trapping mobile hydrogen. This process could be a reason for the molecular hydrogen diffusion during light-soaking [47-49]. We therefore postulate that the large structural changes reported above are macroscopic manifestations of molecular 
K.H. Kim et al.: Light induced electrical and macroscopic changes in hydrogenated polymorphous silicon solar cells

hydrogen accumulation at the interface between the substrate and the PIN stack.

However, there is still a question remaining about the fast diffusion of hydrogen. As a matter of fact, it is reported that hydrogen diffusion in a-Si:H is more moderate than the result presented here $[37,48,49]$. Nevertheless, one can still find the difference in the hydrogen diffusivity between pm-Si:H and a-Si:H, recalling the abrupt disappearance of exodiffusion peak at $350{ }^{\circ} \mathrm{C}$ (Fig. 7) while infrared absorption measurements show only small changes in Si-H bond concentration (Fig. 6). Therefore, such fast hydrogen diffusion cannot originate from $\mathrm{Si}-\mathrm{H}$ bond breaking, but from molecular hydrogen in the material. As mentioned above, molecular hydrogen could exist either in microvoids or at the $p$-layer/substrate interface, and it could have effused out during light-soaking by stress relaxation observed in Raman and AFM studies (Figs. 2 and 3). It has been reported that molecular hydrogen can diffuse faster in a highly inhomogeneous material such as pm-Si:H [38]. In addition, such diffusion would be even accelerated if the material experiences a volume expansion, providing larger space to hydrogen. As a matter of fact, there has been a great deal of research on lightinduced volume changes [50]. Various beam bending experiments have been performed using samples consisting of long and narrow pieces of thin glass or quartz substrates coated with a-Si:H [51-57]. These results reveal that lightinduced volume expansion follows a stretched exponential behavior, usually showing saturation at $d V / V \sim 10^{-3}[29]$. This phenomenon has also been connected with hydrogen motion, as light-induced volume changes have been shown to depend on the hydrogen content of the film [29]. "On-the-edge" or mixed phase materials grown under high hydrogen dilution and having improved order result in solar cells with significantly reduced light-induced degradation. Interestingly enough, these materials show the fastest and largest photo-expansion amongst many different aSi:H materials $[29,58]$. Their large photo-induced volume change prompts comparison to the macroscopic evolution of our pm-Si:H solar cells. In other words, the volume expansion of the film is a product of the stress being relieved, and is particularly important at the $p$-layer/substrate interface.

Turning now to the different behavior of the a-Si:H and pm-Si:H solar cells (Fig. 1), one should also consider the different processing conditions of a-Si:H and pm-Si:H materials (notably vastly different hydrogen dilution and ion-bombardment conditions) which could induce different modification of the p-type a-SiC:H layer of the solar cells. Indeed, the deposition conditions of the pm-Si:H layer could strongly modify the hydrogen content and bonding configurations in the $p$-layer, even if the p-type a-SiC:H layer was deposited under the same conditions for both the a-Si:H and pm-Si:H PIN solar cells. As atomic hydrogen has a high diffusivity in boron doped a-SiC:H [41], it is even more likely that deposition conditions involving high hydrogen dilution will modify the p-type a-SiC:H layer and weaken the interface between the substrate and the $p$ doped layer. The fact that we study PIN stacks and not just intrinsic layers may also be the reason for the exodiffusion peak at $350{ }^{\circ} \mathrm{C}$ (Fig. 7) it has been reported elsewhere [40]. Therefore, we suggest that pm-Si:H deposition conditions may lead to a fragile $p$-layer/substrate interface, which can be further damaged during light-soaking of the solar cells. This is supported by the low temperature sharp spikes in the exodiffusion result (Fig. 7). Indeed, those sharp spikes evidence molecular hydrogen escaping from cavities at relatively low temperature. The hydrogen evolving from these cavities must have been accumulated during light-soaking. Even if AFM and SEM results in Figure 9 allow us to detect significant macroscopic changes only after quite long light-soaking times (16 hrs), small macroscopic changes could already have taken place at the early stages of light-soaking, as supported by the in-situ Raman and AFM studies shown in Figures 3 and 4.

Another interesting aspect of the macroscopic defect creation can be seen in Figure 10, wherein groups of many small holes are found in the AFM image along with larger ones. The size distribution of the holes shows a high density of small ones ( few $\mu \mathrm{m})$, and few larger ones (as large as $20 \mu \mathrm{m}$ ). Considering the fact that small holes are locally grouped, the origin of the large hole might be related to the grouping of small ones. Assuming that the holes are a result of local stress relief, a region where small holes are grouped is most likely less rigid than nearby areas, and when those areas crack and peel-off during light-soaking, compressive stress is relaxed. Large cracked holes could be created through such stress release-crack cycle while more areas are cracked and peeled-off.

The initial infrared absorption increase of pm-Si:H PIN during light-soaking can be explained in the framework of Branz model, where mobile hydrogen is emitted by photocarrier recombination, creating dangling bond. Created mobile hydrogen travels around in the material, and it is captured by another dangling bond and recycled into another $\mathrm{Si}-\mathrm{H}$ bond [59]. In this cycle, re-trapped hydrogen is assumed to originate from $\mathrm{Si}-\mathrm{H}$ bond breaking. However, if a large amount of mobile hydrogen exists in the material (for instance molecular hydrogen), and then the number of hydrogen atoms captured by dangling bonds can be larger than the number of hydrogen atoms created by $\mathrm{Si}-\mathrm{H}$ bond-breaking. The presence of molecular hydrogen in pm-Si:H PIN solar cells, suggested by the exodiffusion spectra (Fig. 7) may cause the fast hydrogen diffusion and initial increase in Si-H bonding (Figs. 6, 7) during light-soaking. Indeed, our result on hydrogen diffusion after light-soaking of pm-Si:H PIN solar cells is found to be much more active than that of a-Si:H in literature [60]. Such an active hydrogen evolution could be also explained by the existence of molecular hydrogen. Furthermore, a multi-body motion model has been proposed in which light-induced molecular hydrogen formation mediated by (another) interstitial molecular hydrogen [42]. In the model, atomic hydrogen comes to passivate a newly created dangling bond left by another atomic hydrogen parted from bond centered position, and two hydrogen atoms form a molecular hydrogen or interstitial hydrogen. This mechanism of bond centered hydrogen creation and 

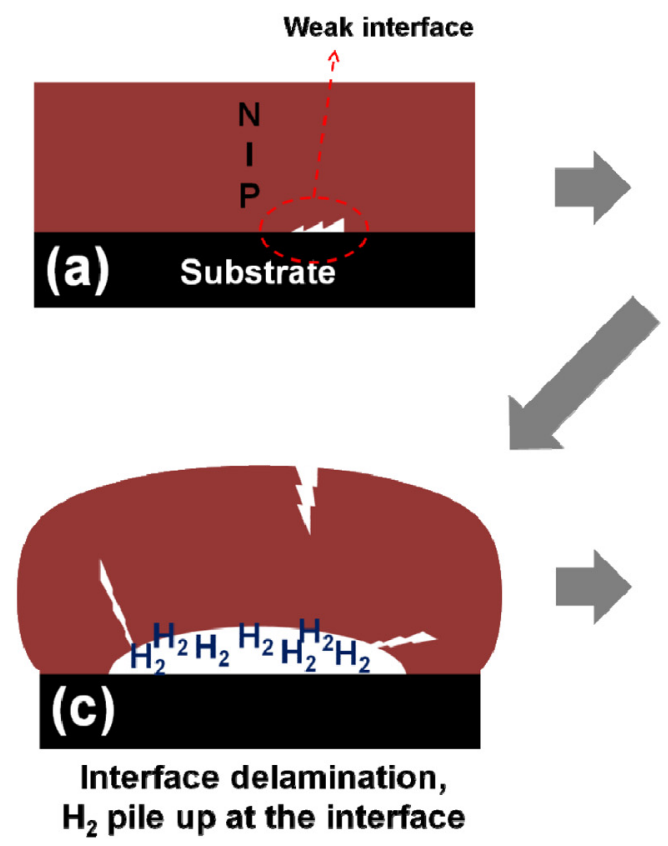
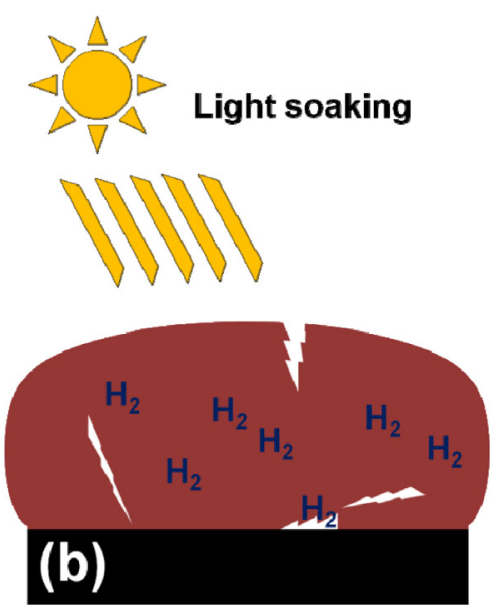

Stress relaxation, Isotropic $\mathbf{H}_{\mathbf{2}}$ effusion

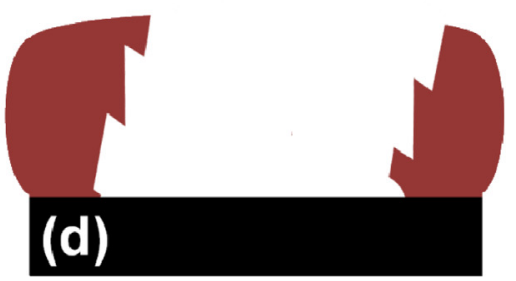

Hole and crack creation

Fig. 11. Diagrammatical representation of proposed mechanism for structural defect formation through localized delamination. See text for description.

annihilation at the very beginning of the light-soaking process indicates that bond centered hydrogen could play the role as an intermediate precursor [35]. It may seem difficult for molecular hydrogen to spontaneously dissociate into atomic hydrogen. Indeed, molecular hydrogen in free space is more stable than $\mathrm{Si}-\mathrm{H}$ bond. However, the energy level of molecular hydrogen in silicon is much less stable than in free space $[61,62]$. Moreover, the existence of not only molecular hydrogen, but also diatomic spices in silicon has been reported [63] and recent works have reported on strain-induced dissociation of molecular hydrogen, in particular at vicinity of strained Si-Si bonds [64,65]. As a matter of fact, we have shown that light-soaking on pmSi:H PIN solar cells is accompanied by a large amount of stress relaxation, as seen in Figures 2-5.

The structural studies can be gathered to propose the macroscopic defect creation scenario shown in Figure 11. In the as-deposited state (Fig. 11a), the pm-Si:H solar cell has a weak film/substrate interface due to the process conditions of the pm-Si:H intrinsic layer. Then, light-soaking (Fig. 11b) introduces volume changes and stress relaxation, molecular hydrogen in the material becomes mobile and isotropically diffuses to the film free surface as well as to the interface with the substrate where it can accumulate and form hydrogen cavities (Fig. 11c). This delamination continues to release built-in "compressive" stress of the film, and the stress relaxation will eventually result in the formation of mechanical defects such as cracks, mounds and holes (Fig. 11d), as well as the accumulation of hydrogen at the interface. Based on the above scenario we propose that the unusual evolution of pm-Si:H solar cell parameters, particularly rapid $J_{s c}$ decrease (Fig. 1), is related to the diffusion of molecular hydrogen, resulting in a reduction of active solar cell area due to delamination. However such delamination can hardly account for the observed increase in $V_{o c}$, which in the literature has been related to dissociation of B-H complexes [18], hydrogen evolution from nanocrystals [21], and light-induced defect states re-distribution at $p / i$ interface [22].

At last, it should be mentioned that a-Si:H also shows large macroscopic structural changes when annealed at $350{ }^{\circ} \mathrm{C}[45,46]$ and irreversible solar cell degradation when light-soaked under 50 suns at $130{ }^{\circ} \mathrm{C}[66,67]$. These extreme conditions lead to enhanced hydrogen motion at the origin of the reported macroscopic structural changes in both films and a-Si:H solar cells. Interestingly, our results on pm-Si:H solar cells show that such irreversible changes can take in this material under standard light-soaking conditions. We attribute this to the peculiar nanostructure of pm-Si:H which provides good environment for hydrogen diffusion [36], and to the presence of weakly bonded hydrogen in the material (see Fig. 7). Therefore, 
K.H. Kim et al.: Light induced electrical and macroscopic changes in hydrogenated polymorphous silicon solar cells

one can conclude that the reported degradation kinetics of pm-Si:H PIN solar cells is an extreme case of a-Si:H solar cells, which also show hydrogen induced structural changes under extreme conditions.

\section{Summary and conclusions}

We have performed a detailed study on light-induced changes in a-Si:H and pm-Si:H PIN solar cells deposited on various substrates and characterized these changes by a wide range of techniques. We have observed that lightsoaking induces an increase of $V_{o c}$ and a fast drop of $J_{s c}$ in pm-Si:H PIN solar cells. The changes in solar cell parameters are correlated to changes in hydrogen incorporation and the structural properties of the material, such as stress relaxation. The experimental results support the hypothesis that light-soaking results in the formation of cavities at the interface between the substrate and the $p$-layer which are progressively filled by molecular hydrogen during light-soaking. This process weakens this interface and causes mechanical defects such as partial delamination, cracks and holes. This is an often forgotten aspect of the so-called SWE. Indeed our results show that besides the creation of electronic defects, macroscopic defects related to the delamination of the $\mathrm{SnO}_{2} / p$-layer interface and $\mathrm{H}_{2}$ diffusion should be considered. This is particularly true in the case of pm-Si:H solar cells, for which a fast initial drop in $J_{s c}$ has been explained by the delamination of the interface at the $\mathrm{SnO}_{2} / p$-layer interface.

This work was performed in the TOTAL-LPICM Joint PV Research Team.

\section{References}

1. D.L. Staebler, C.R. Wronski, Appl. Phys. Lett. 31, 292 (1977)

2. M. Vanecek, O. Babchenko, A. Purkrt, J. Holovsky, N. Neykova, A. Poruba, Z. Remes, J. Meier, U. Kroll, Appl. Phys. Lett. 98, 163503 (2011)

3. J.Y. Ahn, K.H. Jun, K.S. Lim, M. Konagai, Appl. Phys. Lett. 82, 1718 (2003)

4. P. Roca i Cabarrocas, P. St'ahel, S. Hamma, Y. Poissant, Proc. 2nd World Conference on Photovoltaic Solar Energy Conversion, p. 355 (Vienna, Autralia, 1998)

5. P. Roca i Cabarrocas, A. Fontcuberta i Morral, Y. Poissant, Thin Solid Films 403-404, 39 (2002)

6. P. Roca i Cabarrocas, J. Non-Cryst. Solids 266-269, 31 (2000)

7. A. Fontcuberta i Morral, P. Roca i Cabarrocas, C. Clerc, Phys. Rev. B 69, 125307 (2004)

8. Y.M. Soro, A. Abramov, M.E. Gueunier-Farret, E.V. Johnson, C. Longeaud, P. Roca i Cabarrocas, J.P. Kleider, J. Non-Cryst. Solids. 354, 2092 (2008)

9. M. Meaudre, R. Meaudre, R. Butte, S. Vignoli, C. Longeaud, J.P. Kleider, P. Roca i Cabarrocas, J. Appl. Phys. 86, 946 (1999)
10. Y. Poissant, P. Chatterjee, P. Roca i Cabarrocas, J. NonCryst. Solids 299-302, 1173 (2002)

11. M. Brinza, G.J. Adriaenssens, A. Abramov, P. Roca i Cabarrocas, Thin Solid Films 515, 7504 (2007)

12. P. Roca i Cabarrocas, J.B. Chevrier, J. Huc, A. Lloret, J.Y. Parey, J.P.M. Schmitt, J. Vac. Sci. Technol. A 9, 2331 (1991)

13. J. Jang, S.Y. Lee, Appl. Phys. Lett. 52, 1401 (1988)

14. L. Yang, L. Chen, Mater. Res. Soc. Symp. Proc. 336, 669 (1994)

15. P. Siamchai, M. Konagai, Appl. Phys. Lett. 67, 3468 (1995)

16. M. Isomura, H. Yamamoto, M. Kondo, A. Matsuda, Proceedings of the Second World Conference and Exhibition on Photovoltaic Solar Energy Conversion, 6-10 July 1998 (European Commission, Vienna, 1998), p. 925

17. C. Longeaud, J.P. Kleider, M. Gauthier, R. Brüggemann, Y. Poisant, P. Roca i Cabarrocas, Mater. Res. Soc. Symp. Proc. 557, 501 (1999)

18. P. St'ahel, P. Roca i Cabarrocas, P. Sladek, M.L. Theye, MRS Symp. Proc. Ser. 507, 649 (1998)

19. M. Isomura, M. Kondo, A. Matsuda, Jpn J. Appl. Phys. 39, 3339 (2000)

20. K. Lord, B. Yan, J. Yang, S. Guha, Appl. Phys. Lett. 79, $3800(2001)$

21. J. Yang, K. Lord, B. Yan, A. Banerjee, S. Guha, Mater. Res. Soc. Symp. Proc. 715, A26.1.1 (2002)

22. E.V. Johnson, F. Dadouche, M.E. Gueunier-Farret, J.P. Kleider, P. Roca i Cabarrocas, Phys. Stat. Sol. A 207, 691 (2010)

23. V. Nadazdy, M. Zeman, Phys. Rev. B 69, 165213 (2004)

24. Y. Wang, O. Matsuda, T. Serikawa, K. Murase, J. Phys. IV 10, Pr7-259 (2000)

25. J.M. Owens, D. Han, B. Yan, J. Yang, K. Lord, S. Guha, Mat. Res. Soc. Symp. Proc. 762, A4.5.1 (2003)

26. D.M. Bhusari, A.S. Kumbhar, S.T. Kshirsagar, Phys. Rev. B 47, 6460 (1993)

27. D. Beeman, R. Tsu, M.F. Thorpe, Phys. Rev. B 32, 874 (1985)

28. P. Roura, J. Farjas, P. Roca i Cabarrocas, J. Appl. Phys. 104, 073521 (2008)

29. E. Stratakis, E. Spanakis, P. Tzanetakis, H. Fritzsche, S. Guha, J. Yang, Appl. Phys. Lett. 80, 1734 (2002)

30. L. Vincent, P. Soillev, IEEE Trans. Pattern Anal. Mach. Intell. 13, 583 (1991)

31. S. Beucher, F. Meyer, The watershed transformation in Mathematical Morphology in Image Processing, edited by E.R. Dougherty (Marcel Dekker, New York, 1992), pp. $433-481$

32. M.H. Brodsky, M. Cardona, J.J. Cuomo, Phys. Rev. B 16, 3556 (1977)

33. W.B. Jackson, C.C. Tsai, Phys. Rev. B 45, 6564 (1992)

34. S. Lebib, P. Roca i Cabarrocas, Eur. Phys. J. Appl. Phys. 26, 17 (2004)

35. R. Darwich, P. Roca i Cabarrocas, S. Vallon, R. Ossikovski, P. Morin, K. Zellamam, Philos. Mag. B 72, 363 (1995)

36. F. Kail, S. Fellah, A. Abramov, A. Hadjadj, P. Roca i Cabarrocas, J. Non-Cryst. Solids 352, 1083 (2006)

37. A.H. Mahan, W. Beyer, B.L. Williamson, J. Yang, S. Guha, Philos. Mag. Lett. 80, 647 (2000) 
38. F. Kail, J. Farjas, P. Roura, P. Roca i Cabarrocas, Phys. Rev. B 80, 073202 (2009)

39. J. Zhou, M. Kumeda, T. Shimizu, J. Non-Cryst. Solids 195, 76 (1996)

40. N. Pham, Y. Djeridane, A. Abramov, A. Hadjadj, P. Roca i Cabarrocas, Mat. Sci. Eng. B 159-160, 27 (2009)

41. F. Kail, A. Hadjadj, P. Roca i Cabarrocas, Thin Solid Films 487, 126 (2005)

42. C. Longeaud, D. Roy, O. Saadane, Phys. Rev. B 65, 085206 (2002)

43. G.E. Jellison, F.A. Modine Jr., Appl. Phys. Lett. 69, 371 (1996)

44. P. Agarwal, A. Srivastava, D. Deva, J. Appl. Phys. 101, 083504 (2007)

45. H.R. Shanks, C.J. Fang, L. Ley, M. Cardona, F.J. Demond, S. Kalbitzer, Phys. Stat. Sol. B 100, 43 (1980)

46. H.R. Shanks, L. Ley, J. Appl. Phys. 52, 811 (1981)

47. H.M. Branz, Phys. Rev. B 59, 5498 (1999)

48. H.M. Cheong, S.H. Lee, B. Nelson, A. Mascharenas, S.K. Deb, Appl. Phys. Lett. 77, 2686 (2000)

49. H.M. Branz, S. Asher, H. Gleskova, S. Wagner, Phys. Rev. B 59, 5513 (1999)

50. P. Tzanetakis, Sol. Eng. Mater. Sol. Cells 78, 369 (2003)

51. T. Hatano, Y. Nakae, H. Mori, K. Ohkado, N. Yoshida, S. Nonomura, M. Itoh, A. Masuda, H. Matsumura, Thin Solid Films 395, 84 (2001)

52. S. Nonomura, N. Yoshida, T. Gotoh, T. Sakamoto, M. Kondo, A. Matsuda, S. Nitta. J. Non-Cryst. Solids 266-269, 474 (2000)
53. T. Sakamoto, N. Yoshida, H. Harada, T. Kishida, S. Nonomura, T. Gotoh, M. Kondo, A. Matsuda, T. Itoh, S. Nitta, J. Non-Cryst. Solids 266-269, 481 (2000)

54. K. Shimizu, T. Tabuchi, K. Hattori, H. Kida, H. Okamoto, Mater. Res. Soc. Symp. Proc. 507, 735 (1998)

55. T. Gotoh, S. Nonomura, M. Nishio, N. Masui, S. Nitta, M. Kondo, A. Matsuda. J. Non-Cryst. Solids 227-230, 263 (1998)

56. T. Gotoh, S. Nonomura, M. Nishio, S. Nitta, M. Kondo, A. Matsuda, Appl. Phys. Lett. 72, 2978 (1998)

57. N. Yoshida, Y. Shobajima, H. Kamiguchi, T. Ida, T. Hatano, H. Mori, Y. Nakae, M. Itoh, A. Masuda, H. Matsamura, S. Nonomura, J. Non-Cryst. Solids 299-302, $516(2002)$

58. H. Fritzsche, Annu. Rev. Mater. Res. 31, 47 (2001)

59. H.M. Branz, Sol. Eng. Mater. Sol. Cells 78, 425 (2003)

60. P.V. Santos, N.M. Johnson, R.A. Street, Phys. Rev. Lett. 67, 2686 (1991)

61. W.B. Jackson, Curr. Opin. Solid State Mater. Sci. 1, 562 (1996)

62. C.G. Van de Walle, Phys. Rev. B 49, 4579 (1994)

63. K.J. Chang, D.J. Chadi, Phys. Rev. Lett. 62, 937 (1989)

64. S.K. Estreicher, J.L. Hastings, P.A. Fedders, Phys. Rev. B 57, R12663 (1988)

65. S.K. Estreicher, J.L. Hastings, P.A. Fedders, Appl. Phys. Lett. 70, 432 (1997)

66. D.E. Carlson, K. Rajan, Appl. Phys. Lett. 68, 28 (1996)

67. D.E. Carlson, K. Rajan, Appl. Phys. Lett. 69, 1447 (1996) 